\title{
HOW YOUNG POPULATION MAKES PERSONAL FINANCE DECISIONS? EVIDENCE FROM NORTH MACEDONIA
}

\begin{abstract}
Psychological factors, among which the key factor being the risk attitude, combined with the socio-demographic factors, define the person's behavior and activity on the financial markets, as well as the decision-making regarding personal finances. The aim of this research is to analyze the decision-making process regarding financial choices of the young population in North Macedonia and to further explain young people's motives for the proposed decision and the conditions under which such decision was made. The research was conducted through an AHP-based questionnaire that was distributed to respondents younger than 35 years. According to the obtained results, the respondents value stability the most, hence their primary choice is investment in property and luxury goods. Young people are less inclined to invest, especially in the more complex financial instruments. That being the case, apart from the campaigns already created, further encouraging young people to make better and more informed decisions is necessary.
\end{abstract}

Keywords: financial decision-making, personal finance, young population, risk attitude, AHP

\section{Introduction}

People make various financial choices in accordance to their desires, motives, attitudes, affinities and goals, but mostly, individual willingness to take risks. Personal finance is a research area that gains momentum, especially when taking into account the increased attention to the concept of risk in the business environment, due to the greater awareness of risks after the series of corporate scandals, the global financial and economic crisis, as well as the current pandemic of Covid-19. This research area is immensely popular nowadays due to the intensified interest in inserting psychology in the economic sciences and answering the hitherto unanswered questions regarding the human behavior. What is specific for this research though, is its main target: the young population in North Macedonia as well as the influence on young people's financial decision making, which contributes to the originality of this research.

\section{Literature Review}

Individuals' risk attitudes, their perception of risk and consequently their actions, all considered as endogenous human characteristics are explained by the social, cultural, demographic, cognitive, and emotional aspects. The empirical literature provides various findings consistent with the presence of psychological individual-specific factors (Campbell, 2006) and financial knowledge and literacy (Carlin et al., 2012) influencing investors' behavior and financial decision-making. Individual risk taking is relative in 
ISAHP Article: A Style Guide for Paper Proposals To Be Submitted to the International Symposium on the Analytic Hierarchy Process 2020, Web Conference.

different situations (Tversky et al., 1981). In the existing literature we have not found a reference for research like ours in North Macedonia.

\section{Hypotheses/Objectives}

The aim of this research is to analyze the decision-making process regarding financial choices of the young population in North Macedonia and to further explain young people's motives for the proposed decision and the conditions under which such decision was made. We hypothesize that risk attitude is a determinant of a decision-making process to a great extent. Furthermore, financial decision-making is limited by the practical possibilities of exercising financial choices and is immensely influenced by the domestic financial system and the economic environment.

\section{Research Design/Methodology}

In order to evaluate the young population perspective on saving, spending and/or investing assets, we have created a questionnaire. Besides the demographic information, such as: gender, age and level of education, the questionnaire was aimed at determining their risk attitude, which is an immensely important criterion when making such decisions regarding the personal finance management. The respondents were asked a hypothetical question to decide how will they manage their money, supposedly they have inherited 10000 EUR. The alternatives were selected based on their common habits and preference and the characteristics of the Macedonian financial system, and they are the following five: investment in stocks, saving in form of bank deposit, buying a life insurance policy, keeping cash/spending or investment in capital goods (property or luxury goods). First, the respondents were asked to assess the following seven criteria regarding the goal (how they will manage their money): return, volatility, safety, complexity, liquidity, accessibility and stability by using the intensity of importance scale of Saaty (Cvetkoska and Begicevic-Redzep, 2016, p. 244). Then, they were asked to assess the alternatives regarding each criterion by using the same scale. The questionnaire was distributed by e-mail to 9 respondents younger than 35 years. They were facing with this type of questionnaire based on AHP for the first time, given that this multi-criteria decision making method is relatively new in our country and has only recently found application. However, the responses were obtained in two weeks in May 2020.

\section{Data/Model Analysis}

The created AHP model in our paper is given in Figure 1. Based on the obtained data from the respondents for the pair-wise comparisons for the criteria and the alternatives, we have used the geometric mean (Aczel and Saaty, 1983). The weight coefficients for the criteria: return, volatility, safety, complexity, liquidity, accessibility and stability are: $0.0852,0.0503,0.2642,0.0454,0.1156,0.1416$ and 0.2978 . The consistency ratio is below 0.0586 , which means that the pair wise comparisons are consistent. In table 1 are presented the local priorities of each alternative regarding each criterion, as well as their overall priorities, based on which the ranking is made.

Figure 1. Development of the AHP model 


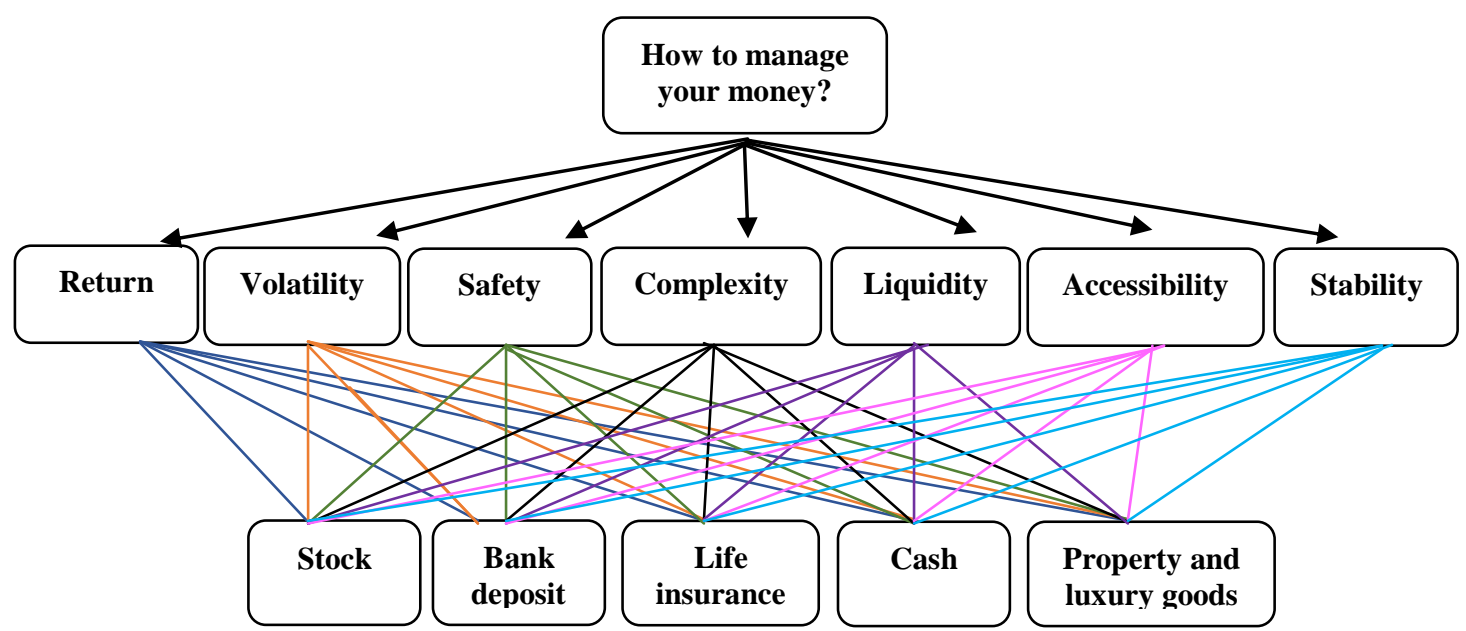

Source: Authors

Table 1. Summarized results for the alternatives

\begin{tabular}{cccccc}
\hline & Stock & Deposit & Life Insurance & Cash & Property \\
\hline Return & 0.5713 & 0.1185 & 0.1850 & 0.0387 & 0.0865 \\
Volatility & 0.0495 & 0.2425 & 0.0646 & 0.1106 & 0.5328 \\
Safety & 0.0424 & 0.1705 & 0.1480 & 0.0420 & 0.5970 \\
Complexity & 0.0436 & 0.3285 & 0.0436 & 0.4482 & 0.1361 \\
Liquidity & 0.0756 & 0.2262 & 0.0333 & 0.5205 & 0.1444 \\
Accessibility & 0.0720 & 0.1726 & 0.0369 & 0.4909 & 0.2275 \\
Stability & 0.0606 & 0.1808 & 0.1971 & 0.0340 & 0.5275 \\
Overall & 0.0996 & 0.1865 & 0.1280 & 0.1789 & 0.4069 \\
priorities & $\mathbf{5}$ & $\mathbf{2}$ & $\mathbf{4}$ & $\mathbf{3}$ & $\mathbf{1}$ \\
Ranking & $\mathbf{5}$ & & &
\end{tabular}

Source: Own calculations

\section{Limitations}

The findings of this study have to be seen in light of some limitations. The obtained results are based on the group decision-making with AHP in a sample of 9 respondents under the age of 35. Therefore, the sample may be insufficient to be considered representative of the whole young population. In addition, the AHP method is still new in our country, thus slight issues occurred while collecting the data.

\section{Conclusions}

The decision-making regarding personal finance among young people is a multi-layered, social and economic issue, which is related to the level of youth unemployment and underemployment. When it comes to decision-making regarding personal finance, another emerging problem is the lack of financial literacy in North Macedonia. That being said, the motive for saving and investing is secondary, despite the primary need to provide a decent life. Insufficient investment in our country is a result of the modest supply of attractive financial instruments, low living standard, the risk culture and the traditional habits of consumption and savings. Finally, it should be noted that this research is relevant to the extent that it brings a better understanding of how individuals make financial decisions, which may allow financial institutions and governments to 
ISAHP Article: A Style Guide for Paper Proposals To Be Submitted to the International Symposium on the Analytic Hierarchy Process 2020, Web Conference.

design programs in order to promote financial inclusion and encourage people to make better decisions, particularly in developing economies.

\section{Key References}

Aczel, J., \& Saaty, T. L. (1983). Procedures for synthesizing ratio judgment. Journal of Mathematical Psychology, 27, pp. 93-102.

Campbell, J.Y. (2006), Household finance, The Journal of Finance, 61(4), pp. 15531604.

Carlin, B. I. \& Robinson, D. T. (2012), Financial education and timely decision support: Lessons from junior achievement, American Economic Review, 102(3), pp. 305- 308.

Cvetkoska, V. \& Begicevic-Redzep, N. (2016). Applying the analytic hierarchy process to rank city-branches, in Book of Proceedings of the XV International Symposium SYMORG2016, Zlatibor, Serbia, University of Belgrade, Faculty of Organizational Sciences, Belgrade, pp. 241-252.

Tversky, A. \& Kahnemann, D. (1981), The framing of decisions and the psychology of choice, Science, 211 (4481), pp. 453-458. 